\title{
PRODUÇÃO DE MUDAS DE ABOBRINHA HÍBRIDA EM DIFERENTES SUBSTRATOS E NÍVEIS DE ESTRESSE SALINO
}

\author{
Yuri Ferreira Amorim ${ }^{1 *}$ \\ ${ }^{1}$ Universidade Estadual do Sudoeste da Bahia. Praça Primavera, 40 - Bairro Primavera, Itapetinga - BA, CEP: 45700-000. \\ *Autor para correspondência: yfamorim@hotmail.com
}

\begin{abstract}
RESUMO: O objetivo desse trabalho foi comparar substratos e avaliar níveis de salinidade sobre a emergência e qualidade de plântulas de abobrinha-italiana LA BELLE F1. O experimento foi realizado em casa de vegetação, os tratamentos foram distribuídos em blocos casualizados em esquema fatorial $3 \times 5$, correspondente a três tipos de substratos (Vivatto Slim Plus ${ }^{\circledR}$, Esterco bovino + areia + solo e Bioplant $\left.{ }^{\circledR}\right)$ e cinco níveis de salinidade $(0 ; 1,0 ; 2,0$; 3,0 e 4,0 dS. $\mathrm{m}^{-1}$ ) com três repetições. Os parâmetros taxa de germinação, índice de velocidade de emergência, diâmetro de caule, altura da parte aérea, comprimento de raiz, massa fresca e seca da raiz e parte aérea foram submetidas ao Teste $F(p>0,05)$. Não houve significância para a interação salinidade x substrato, havendo diferença significativa para o fator de variação substrato, exceto o peso seco de raiz. Os níveis de salinidade na água não interferiram na emergência e no crescimento das plântulas, apenas foi significativo o diâmetro do caule e massa fresca da parte aérea, verificando que a abobrinha tolera o nível de salinidade até $4 \mathrm{dS} . \mathrm{m}^{-1}$ na fase de muda. 0 substrato Vivatto $₫$ apresentou o melhor desempenho pelo teste Tukey $(P>0.05)$.
\end{abstract}

PALAVRAS- CHAVE: crescimento, índice de velocidade de emergência, Vivatto Slim Plus ${ }_{\text {. }}$

\section{PRODUCTION OF HYBRID SEEDLINGS OF ZUCCHINI ON DIFFERENT SUBSTRATES AND LEVELS OF SALT STRESS}

\begin{abstract}
The objective of this study was to compare substrates and assess levels of salinity on the emergence and seedling quality of zucchini-Italian F1 LA BELLE. The experiment was conducted in a greenhouse, the treatments were distributed in randomized blocks in factorial scheme $3 \times 5$, corresponding to the three types of substrates (Vivatto Slim Plus ${ }^{\circledR}$, cow manure and soil sand Bioplant ${ }^{\circledR}$ ) and five levels of salinity $(0 ; 1.0 ; 2.0 ; 3.0$ and $4.0 \mathrm{dS} \mathrm{m}$-1) with three replicates. The germination rate parameters, emergency speed index, stem diameter, height of the aerial part, root length, fresh and dry matter of roots and aerial parts were submitted to F-test $(p>0.05)$. There was no significant interaction for salinity $x$ substrate, no significant difference for the factor of substrate variation, except root dry weight. Salinity levels in the water not interfered in the emergence and seedling growth, was only significant diameter the stem and the fresh mass of shoots, noting that the zucchini tolerate the level salinity up to 4 dS.m-1 in the seedling stage. The Vivatto $®$ substrate showed the best performance by Tukey test $(p>0.05)$.
\end{abstract}

KEY WORDS: growth, emergency speed index, Vivatto Slim Plus ${ }^{\circledR}$.

\section{INTRODUÇÃO}

Pertencente à família Cucurbitaceae (Camargo, 1992), a abobrinha-italiana (Cucurbita pepo L.), também conhecida como abóbora de moita ou de árvore originou-se da região central do México (Filgueira, 2003). As cucurbitáceas ocupam lugar de destaque, sendo de ampla aceitação popular, destacandose entre elas a abobrinha, com grande importância econômica no Brasil (Casaroli et al., 2009), sendo as condições eudafoclimáticas bastante favoráveis ao seu cultivo. Atualmente, a espécie encontra-se entre as dez hortaliças de maior produção e maior valor econômico no país (Carpes et al., 2010).

A produção de mudas consiste em uma das etapas mais importantes do sistema produtivo hortícola, necessitando utilizar insumos de alta qualidade (Silveira 
et al., 2002), destacando o substrato, considerado um dos insumos de maior importância na produção de mudas (Correia et al., 2003). Podendo optar por substratos comerciais, que possuem boa aceitação no mercado e considerados de boa qualidade, mas que implicam em aumentos no custo de produção. Alternativamente, têm-se a opção de formulação de substratos a partir de produtos disponíveis na propriedade ou na região de produção, reduzindo-se o custo final.

0 substrato utilizado deve proporcionar as melhores condições para o aproveitamento do potencial produtivo, devendo apresentar características físicas, químicas e biológicas apropriadas para que possa permitir pleno crescimento das raízes e da parte aérea (Setubal e Neto, 2000), visando produção de mudas de boa qualidade e, consequentemente 0 bom desempenho em campo.

A salinidade do solo e da água são fatores que afetam a germinação de sementes, a formação de mudas, o crescimento e desenvolvimento das plantas e a produção quantitativa e qualitativa das culturas (Tester e Davenport, 2003). Os efeitos destes sais, vão desde a elevação da pressão osmótica, reduzindo a disponibilidade de água para os vegetais (Shannon, 1997), podendo ocorrer efeitos tóxicos de íons específicos provocando injúrias associadas à acumulação excessiva nos tecidos (Flowers e Flowers, 2005).

Pesquisas foram realizadas para avaliar a tolerância das culturas à salinidade com espécies pertencentes à família cucurbitaceae, como o maxixe, o meloeiro (Medeiros et al., 2008; Gurgel et al., 2010; Dias et al., 2010) e a abóbora (Strassburger et al., 2011). Porém, tornam-se necessários estudos com a abobrinha, especialmente quanto ao manejo no suprimento hídrico, sob o uso de águas salinas, enfocando a resposta da planta à salinidade na fase de germinação e vigor das plântulas.

Compreendendo o contexto, este trabalho teve como objetivo avaliar o efeito de substratos comerciais e orgânicos na emergência de plântulas de abobrinha submetidas a diferentes níveis salinos.

\section{MATERIAL E MÉTODOS}

0 experimento foi conduzido em casa de vegetação da Universidade Estadual do Sudoeste da
Bahia, campus de Vitória da Conquista - BA (Latitude $14^{\circ} 53^{\prime}$ S e Longitude $40^{\circ} 48^{\prime} \mathrm{W}$ ), no mês de fevereiro de 2014. Utilizou-se o delineamento em blocos casualizados em esquema fatorial $3 \times 5$ com três repetições, sendo três tipos de substratos (Vivatto Slim Plus $囚$, Esterco bovino + areia + solo e Bioplant $($ ) e cinco níveis de salinidade $\left(0,0 ; 1,0 ; 2,0 ; 3,0\right.$ e 4,0 dS. $\left.\mathrm{m}^{-1}\right)$.

Utilizou-se bandejas de poliestireno de 128 cavidades, previamente desinfectadas. Cada bandeja foi preenchida com três substratos distribuídos aleatoriamente entre blocos e a irrigação com um nível de salinidade. Foram selecionadas nove sementes de abobrinha-italiana por tratamento, sendo uma por cédula da bandeja, totalizando 405 sementes no experimento. Mantiveram-se as bandejas suspensas do chão em ambiente controlado. 0 preparo das soluções foram feitas diariamente com água destilada e cloreto de sódio ( $\mathrm{NaCl}$ ), com o auxílio de condutivímetro para mensurar a condutividade elétrica e as regas realizadas duas vezes ao dia.

A semeadura foi realizada no dia 03 de fevereiro de 2014, após cinco dias foi feita a primeira contagem de emergência das plântulas, estimou-se 0 Índice de Velocidade de Emergência (IVE), registrandose diariamente o número de plântulas emergidas, com parte aérea formada, até o quinto dia quando houve estabilização da emergência, e este foi calculado pela fórmula proposta por Maguire (1962): IVE = E1/N1 + $\mathrm{E} 2 / \mathrm{N} 2+\ldots \mathrm{En} / \mathrm{Nn}$ Onde: IVE = índice de velocidade de emergência. $E 1, E 2, \ldots$ En = número de plântulas normais computadas na primeira contagem, na segunda contagem e na última contagem. N1, N2,... Nn = número de dias da semeadura à primeira, segunda $\mathrm{e}$ última contagem.

Quinze dias após a semeadura foram avaliados: o Diâmetro do Caule (DC) medido com paquímetro digital em mm, a Altura das Plântulas (AP) e o Comprimento da Raiz (CR), ambos medidos com auxílio de uma régua graduada $\mathrm{em} \mathrm{cm}$; e a Massa Fresca da Parte Aérea (MSPA) e da Raiz (MFR), a Massa Seca da Parte Aérea (MSPA) e da Raiz (MSR) em g.planta- ${ }^{-1}$, determinadas retirando-se as plântulas das bandejas, lavando-as para a retirada de todo o substrato e colocando-as em sacos de papel devidamente identificados, pesou-se logo em seguida em balança analítica, para determinação da massa fresca e colocando-as em estufa de o circulação de ar forçada a $65^{\circ} \mathrm{C}$, por 72 horas. Após este período, foram 
retiradas, e novamente, pesadas para determinação da massa da matéria seca.

Avaliou-se simultaneamente a taxa de germinação e dez dias depois do plantio calculou-se a taxa de germinação e as demais características. Os dados obtidos foram submetidos ao Teste $F(P>0,05)$, à análise de variância e as médias dos tratamentos comparadas pelo teste Tukey ao nível de $5 \%$ de probabilidade com 0 auxilio do programa estatístico Sisvar (Versão 5.1).

\section{RESULTADOS E DISCUSSÃO}

Ainteração entre salinidade $x$ substratos não teve efeito significativo $(P<0,05)$ pelo teste $F$ nas características avaliadas (Tabela 1), o que pode ser justificado, pois, a condutividade elétrica do solo ou do substrato aumenta com a deficiência de drenagem no mesmo, assim a lixiviação é uma prática eficiente para reduzir o excesso de sais solúveis na zona radicular das plântulas (Garcia et al., 2007). Portanto, os três substratos utilizados foram eficientes na drenagem da água.

Tabela 1. Resumo da análise de variância para porcentagem de germinação índice velocidade de germinação (IVE), diâmetro de caule (DC), comprimento da parte aérea (CPA), comprimento de raiz (CR), massa fresca da parte aérea (MFPA), massa seca da parte aérea (MSPA), massa fresca da raiz (MFR) e a massa seca da raiz (MSR) da plântula de abobrinha em diferentes substrato e níveis de salinidade da água de irrigação

\begin{tabular}{|c|c|c|c|c|c|c|c|c|c|c|}
\hline FV & GL & $\%$ Ger. & IVE & $\begin{array}{c}\mathrm{DC} \\
(\mathrm{mm})\end{array}$ & $\begin{array}{c}\mathrm{AP} \\
(\mathrm{cm})\end{array}$ & $\begin{array}{c}\mathrm{CR} \\
(\mathrm{cm})\end{array}$ & $\begin{array}{c}\text { MFPA } \\
\left.\text { (g planta }{ }^{-1}\right)\end{array}$ & $\begin{array}{c}\text { MSPA } \\
\left(\text { g planta }^{-1}\right)\end{array}$ & $\begin{array}{c}\text { MFR } \\
\left(\text { g planta }^{-1}\right)\end{array}$ & $\begin{array}{c}\text { MSR } \\
\left.\text { (g planta }{ }^{-1}\right)\end{array}$ \\
\hline Substratos & 2 & $118,0^{\text {ns }}$ & $0,33^{*}$ & $23,1^{*}$ & $37,1^{*}$ & $3,43^{*}$ & $74,38^{*}$ & $5,37^{*}$ & $13,27^{*}$ & $0,22^{\text {ns }}$ \\
\hline Salinidade & 4 & $91,9^{\text {ns }}$ & $0,02^{\text {ns }}$ & $7,11^{*}$ & $0,57^{\mathrm{ns}}$ & $0,67^{\mathrm{ns}}$ & $3,35^{\star}$ & $0,34^{\mathrm{ns}}$ & $1,6^{\text {ns }}$ & $1,1^{\mathrm{ns}}$ \\
\hline Subs. x Salin. & 8 & $166,1^{\text {ns }}$ & $0,1^{\text {ns }}$ & $0,94^{\mathrm{ns}}$ & $0,33^{\text {ns }}$ & $1,28^{\text {ns }}$ & $1,5^{\mathrm{ns}}$ & $0,67^{\mathrm{ns}}$ & $0,96^{\mathrm{ns}}$ & $0,91^{\mathrm{ns}}$ \\
\hline Resíduo & 30 & 93,32 & 0,05 & 0,05 & 1,85 & 4,86 & 3,36 & 0,05 & 0,08 & 0,009 \\
\hline CV $(\%)$ & & 14,83 & 10,41 & 7,90 & 12,67 & 25,96 & 16,30 & 35,02 & 21,00 & 65,94 \\
\hline
\end{tabular}

*- Significativo ao nível de $5 \%$ de probabilidade pelo teste F; " ns- Não significativo ao nível de $5 \%$ de probabilidade.

A produção de mudas é influenciada pela composição do substrato, assim a escolha torna-se muito importante para o sucesso nesta fase (Correia et al., 2003). A influência vai desde a velocidade de emergência, devido a alguns substratos atuarem como barreira física a germinação, retardando a emergência da plântula (Araújo et al., 2011), até no crescimento das mudas. Na Tabela 1, não houve diferença significativa para a taxa de germinação que foi superior à $85 \%$. Ela não foi afetada pelo tipo de substrato, mas influenciou significativamente no IVE das plântulas.
Os substratos comerciais Bioplant ${ }^{\circledR}$ e Vivatto $\circledR$, são utilizados na produção de mudas de cucurbitáceas, mas diferenciam quanto 0 desempenho das mudas entre as espécies desta família, na Tabela 2, o substrato Vivatto $@$ obteve os melhores resultados, e o Bioplant $₫$ os piores entre os três substratos em todas as características analisadas. Para vários autores, o mesmo substrato apresenta os melhores resultados, como foi observado em mudas de pepino (Gazola et al., 2013). Resultados obtidos na avaliação da germinação e crescimento de plântulas de melancieira em diferentes ambientes e substratos constatou que 0 Vivatto $₫$ proporcionou 0 melhor desenvolvimento no IVE (Quinto et al., 2011).

Tabela 2. Médias de percentual de germinação e índice de velocidade de germinação de sementes de abobrinha em diferentes substrato

\begin{tabular}{|c|c|c|c|c|c|c|c|c|}
\hline Substratos & IVE & $\begin{array}{c}\mathrm{DC} \\
(\mathrm{mm})\end{array}$ & $\begin{array}{l}\text { AP } \\
(\mathrm{cm})\end{array}$ & $\begin{array}{l}\text { CR } \\
(\mathrm{cm})\end{array}$ & $\begin{array}{c}\text { MFPA } \\
\left(\text { g }^{\text {planta }}{ }^{-1}\right)\end{array}$ & $\begin{array}{c}\text { MSPA } \\
\left(\text { g planta }^{-1}\right)\end{array}$ & $\begin{array}{c}\text { MFR } \\
\left(\text { g planta }^{-1}\right)\end{array}$ & $\begin{array}{c}\text { MSR } \\
\left(\text { g planta }^{-1}\right)\end{array}$ \\
\hline Vivatto $\AA$ & $1,66 \mathrm{a}$ & $3,17 a$ & $13,00 \mathrm{a}$ & $9,42 \mathrm{a}$ & $15,64 \mathrm{a}$ & $0,77 a$ & $1,69 a$ & $0,13 a$ \\
\hline Esterco bovino+ areia+solo & $1,57 a b$ & $3,06 \mathrm{a}$ & $10,47 b$ & $7,35 \mathrm{~b}$ & $10,57 b$ & $0,70 a b$ & $1,42 a$ & $0,14 a$ \\
\hline Bioplant $₫$ & $1,36 \mathrm{~b}$ & $2,62 b$ & $8,74 \mathrm{c}$ & $8,70 \mathrm{ab}$ & $7,55 \mathrm{c}$ & $0,50 \mathrm{~b}$ & $1,13 b$ & $0,16 \mathrm{a}$ \\
\hline DMS (5\%) & 0,20 & 0,210 & 1,225 & 1,985 & 1,652 & 0,208 & 0,268 & 0,088 \\
\hline CV (\%) & & 7,90 & 12,67 & 25,96 & 16,30 & 35,02 & 21,00 & 65,94 \\
\hline
\end{tabular}

Médias seguidas de mesma letra na coluna não diferem pelo teste de Tukey, a 5 \% de probabilidade. 
Para condutividades elétricas da água (CEa) maiores que 4,80 dS.m ${ }^{-1}$ ocorre um decréscimo significativo na velocidade de emergência das plântulas de abobrinha. Esse efeito pode estar relacionado com os danos causados pelo excesso de sais que aumentam a força de retenção da água no substrato, o que dificulta a entrada de água por embebição (Dias e Blanco, 2010), e/ou pelo efeito da toxicidade iônica, por excesso principalmente de $\mathrm{Na}^{+}, \mathrm{Cl}^{-}, \mathrm{SO}_{4}$ nas células (Taiz e Zeiger, 2009).

Houve efeito significativo dos níveis de salinidade pelo teste $\mathrm{F}$ para as características DC e MFPA das plântulas de abobrinha conforme a análise de variância $(D C=7,11: F$ MFPA=3,35) e a curva da equação de regressão quadrática como se observa na Figura 1 e 2. O nível 3,0 e 2 dS. $\mathrm{m}^{-1}$, respectivamente, proporcionou o maior DC e MFPA (3,23 mm ; 11,97 g planta $^{-1}$ ) comparado com a testemunha $0 \mathrm{dS} . \mathrm{m}$ 1 nível $4 \mathrm{dS} . \mathrm{m}^{-1}$ que obtiveram respectivamente os menores valores para DC $(2,67 \mathrm{~mm})$ e MFPA $(10,23 \mathrm{~g}$ planta $\left.{ }^{-1}\right)$, portanto, 0 aumento da salinidade influenciou positivamente no diâmetro de caule e matéria fresca da parte aérea, até o nível salino 3,0 dS. $\mathrm{m}^{-1}$. Alguns autores trabalhando com melancia, verificaram que a salinidade não influência no diâmetro de caule, e interfere negativamente no crescimento vegetativo (Martins et al., 2013).

Figura 1. Diâmetro de Caule $(\mathrm{mm})$ de plantulas de Abobrinha Italiana em função dos níveis salinos na água de irrigação

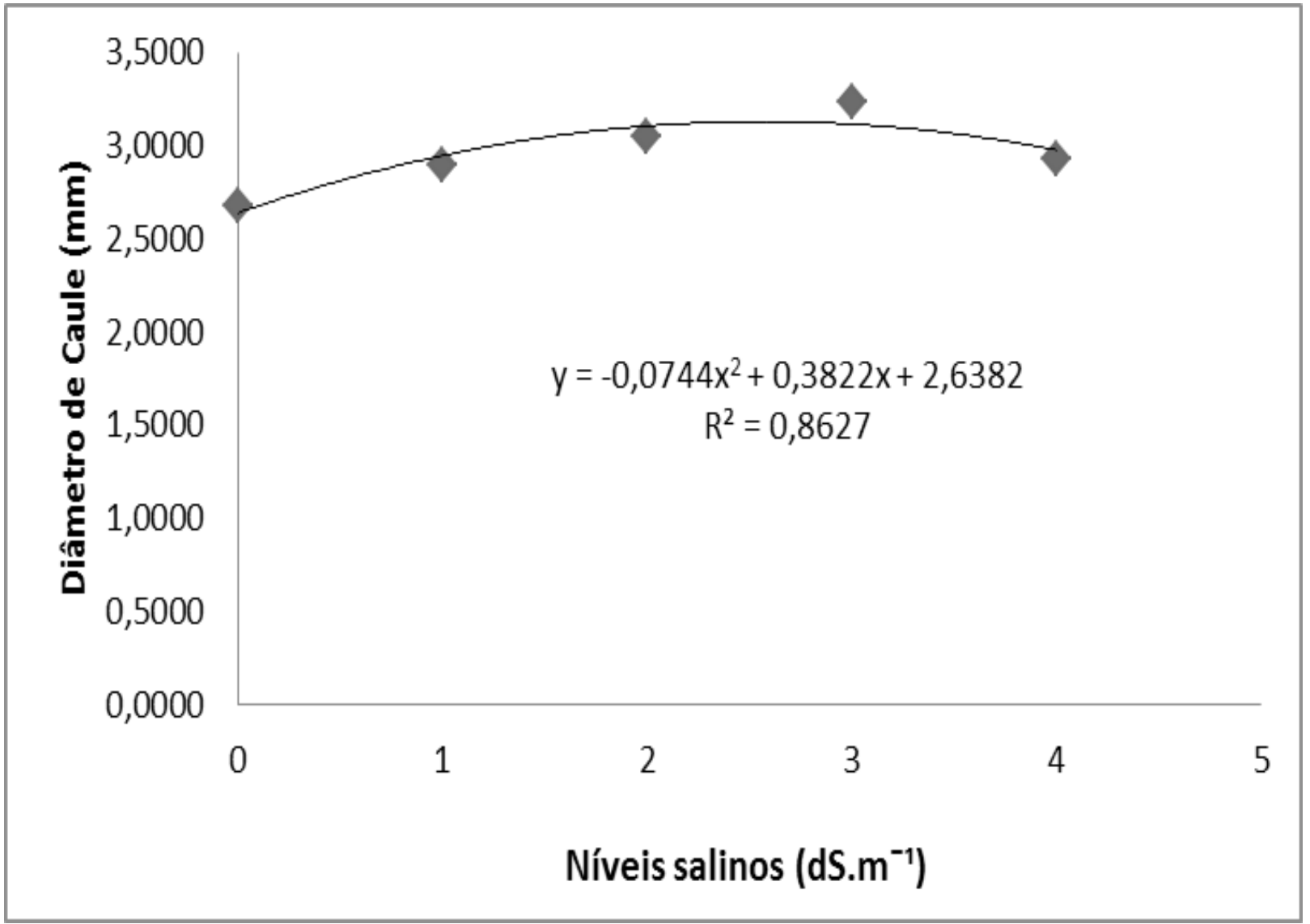


Figura 2. Massa Fresca de Parte Aérea (g.planta ${ }^{-1}$ ) de plantulas de Abobrinha Italiana em função dos níveis salinos na água de irrigação

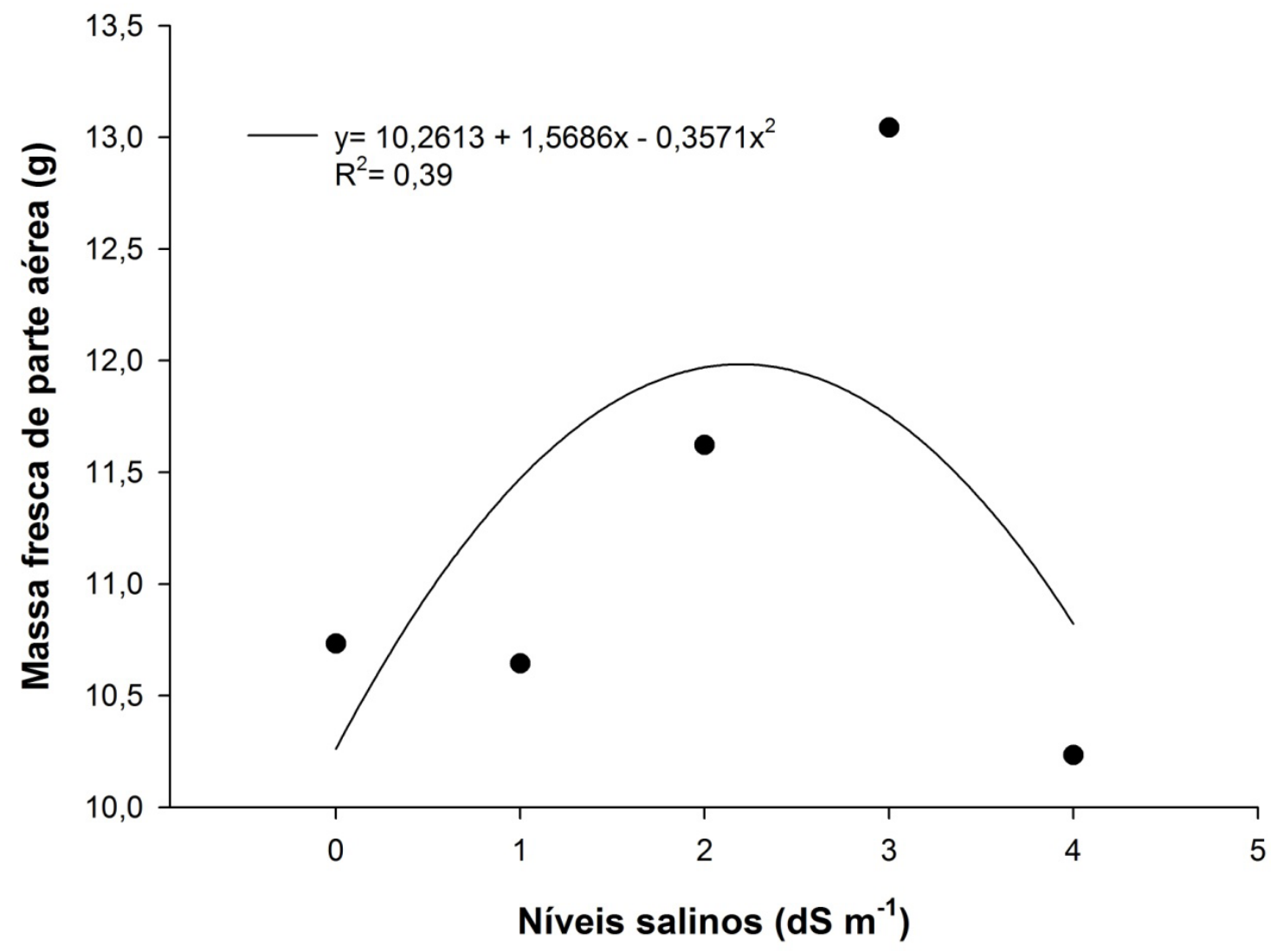

Para as características AP, CR, MPFA, MFR e MSPA, apresentaram efeito significativo para a variável substrato, com se observa na Tabela 1, enquanto que MSR não houve interferência em g planta-1 ${ }^{-1}$. Os piores resultados foram encontrados utilizando o substrato Bioplant $\circledR^{8}$ na cultura da abobrinha, porém, influenciou no melhor desempenho de mudas de pepino, para as características altura da parte aérea, comprimento de raíz, matéria fresca total da plântula e matéria seca total (Gazola et al., 2013). O substrato que influenciou em uma melhor qualidade de mudas foi o Vivatto®, de acordo com os parâmetros avaliados, acompanhado pela mistura (Esterco bovino + areia + solo). Esses resultados possibilitam determinar os substratos que forneceu as maiores quantidades de nutrientes para 0 crescimento da plântula, principalmente pelo peso da massa seca das mesmas (Luz et al., 2004).

Dos níveis de salinidade analisados na água de irrigação, aqueles até $4 \mathrm{dS} \cdot \mathrm{m}^{-1}$, não são limitantes à produção de mudas de abobrinha hibrida LA BELLE F1; O substrato Bioplant ${ }^{\circledR}$ apresentou os piores resultados para DC, AP, MFPA e MFR; O substrato da mistura de esterco bovino + areia + solo apresentou paridade com o Vivatto ${ }^{\circledR}$ na maioria das características analisadas (IVE, DC, MSPA e MFR), indicado para a produção de mudas, com a diminuição de custo de produção; 0 melhor substrato para as condições do experimento foi o Vivatto Slim Plus®.

\section{REFERÊNCIAS BIBLIOGRÁFICAS}

ARAGÃO, C. A.; PIRES, M. M. M. L.; BATISTA, P. F.; DANTAS, B. F. Qualidade de mudas de melão produzidas em diferentes substratos. Revista Caatinga, 2011, 24, 3, 209-214.

CAMARGO, L.S. . As hortaliças e seu cultivo. Campinas: Fundação Cargill, 1992, 97.

CARPES, R. H.; LÚCIO, A. D.; LOPES, S. J.; BENZ, V.; HAESBAERT, F.; SANTOS, D. Variabilidade produtiva e agrupamentos de colheitas de abobrinha italiana 
cultivada em ambiente protegido. Ciência Rural, 2010,40, 264-271.

CASAROLI, D.; GARCIA, D. C.; MENEZES, N. L.; MUNIZ, M. F. B.; MANFRON, P. A. Testes para determinação do potencial fisiológico de sementes de abóbora. Acta Scientiarum Agronomy, 2009, 31, 337 343.

CORREIA, D.; ROSA, M. F.; BEZERRA, F. C.; NORÕES, E. R. V.; ARAUJO, F. B. Uso do pó da casca de coco na formulação de substratos para formação de mudas enxertadas e cajueiro anão precoce. Revista Brasileira de Fruticultura, 2003, 25, 557-558.

DIAS, N. S.; LIRA, R. B.; BRITO, R. F.; SOUSA NETO, O. N.; FERREIRA NETO, M.; OLIVEIRA, M. Produção de melão rendilhado em sistema hidropônico com rejeito da dessalinização de água em solução nutritiva. Revista Brasileira de Engenharia Agrícola e Ambiental, 2010, 14, 755-761.

DIAS, N. S.; BLANCO, F. F. Efeitos dos sais no solo e na planta. In: Manejo da salinidade na agricultura: Estudos básicos e aplicados. Fortaleza, INCT Sal, 2010, 129-140.

FILGUEIRA, F. A. R. Novo manual de olericultura: agrotecnologia moderna na produção e comercialização de hortaliças. Viçosa: UFV, p. 295, 2003.

FLOWERS, T. J.; FLOWERS, S. A. Why does salinity pose such a difficult problem for plant breeders? Agricultural Water Management, 2005, 78, 1, 15- 24.

GARCIA, G. O.; FERREIRA, P. A.; MIRANDA G.; NEVES, J. C. L.; W. B.; SANTOS, D. B. Teores foliares dos macronutrientes catiônicos e suas relações com 0 sódio em plantas de milho sob estresse salino. Idesia, 2007, 25, 3.

GAZOLA, R. N.; CASTILHO, R, M. M.; DINALLI, R. P.; CELESTRINO, T. S.; MÓDENA, C. M. Germinação e crescimento inicial de plântulas de pepino em substratos comerciais. Tecnologia \& Ciência Agropecuária, 2013, $7,3,25-30$

GURGEL, M. T.; GHEYI, H. R.; OLIVEIRA, F. H. T Acúmulo de matéria seca e nutrientes em meloeiro produzido sob estresse salino e doses de potássio. Revista Ciência Agronômica, 2010, 41,18-28.

LUZ, J. M. Q.; BRANDÃO, F. D.; MARTINS, S. T.; MELO, M. Produtividade de cultivares de alface em função de mudas produzidas em diferentes substratos comerciais. B. Uberlândia, Bioscience Journal, 2004, 1, 1, 61-65.

MARTINS, D. C.; RIBEIRO, M. S. S.; SOUZA NETA, M. L.; SILVA, R. T.; GOMES, L. P.; GUEDES, R. A. A.; OLIVEIRA, F. A. Desenvolvimento inicial de cultivares de melancia sob estresse salino. ACSA - Agropecuária Científica no Semi-Árido, 2013, 8, 3, 62-68.

MEDEIROS, J. F.; DIAS, N. S.; BARROS, A. D. Manejo da irrigação e tolerância do meloeiro a salinidade da água de irrigação. Revista Brasileira de Ciências Agrárias, 2008, 3, 242-247.

QUINTO, V. M.; BELTRAME, R. A.; PEREIRA, E.O.; CABANÊZ, P. A.; AMARAL, J. F. T. Germinação e desenvolvimento de plântulas de melancieira em diferentes ambientes e substratos. Revista Verde, 2011, 6, 252-257.

SETÚBAL, J. W.; NETO, C. A. F. Efeito de substratos alternativos e tipos de bandejas na produção de mudas de pimentão. Horticultura Brasileira, 2000, 18, 593-594.

SHANNON, M. C. Adaptation of plants to salinity. Advances in Agronomy, 1997, 60, 75-120.

SILVEIRA, E. B.; RODRIGUES, V.J.L.B.; GOMES, A. M. A.; MARIANO, R. L. R.; MESQUITA, J. C. P. Pó de coco como substrato para produção de mudas de tomateiro. Horticultura Brasileira, 2002, 20, 211-216.

STRASSBURGER,A.S.; NOGUEIRA, R. M.;FONSECA, L. A.; AUMONDE, T. Z. crescimento e produtividade da abobrinha italiana: efeito da concentração iônica da solução nutritiva. Semina: Ciências Agrárias, 2011, 32, 553-564

TAIZ, L.; ZEIGER, E. Fisiologia Vegetal. Porto Alegre: Artmed, 2009, 820.

TESTER, M.; DAVENPORT, R. Na+ tolerance and $\mathrm{Na}+$ transport in higher plants. Annal of Botany, 2003, 91, 5, 503-527. 